JKKP : Jurnal Kesejahteraan Keluarga dan Pendidikan

http://doi.org/10.21009/JKKP

DOI: doi.org/10.21009/JKKP.052.05

E-ISSN : 2597-4521

\title{
MODEL COMPETENCY BASED ASSESSMENT PADA PENGEMBANGAN JOB PERFORMANCE PUBLIC AREA DI HOUSEKEEPING DEPARTMENT
}

\author{
Yoyoh Jubaedah ${ }^{1, a}$, Neni Rohaeni ${ }^{2}$, Nenden Rani Rinekasari ${ }^{3}$, \\ lis Rohmah. $\mathrm{H}^{4}$
}

Email : yoju2010@yahoo.co.id

1,2,3,4 Program Studi Pendidikan Kesejahteraan Keluarga

Fakultas Pendidikan Teknik dan Kejuruan, Universitas Pendidikan Indonesia

\begin{abstract}
Abstrak
Tujuan dari penelitian ini adalah untuk menerapkan model Competency Based Assessment pada pengembangan Job Performance Public Area di Housekeeping Department. Target khusus yang ingin dicapai dari penelitian ini adalah menghasilkan: (1) Model Competency Based Assessment pada pengembangan Job Performance Public Area di Housekeeping Department, (2) Alat Penilaian Job Performance Public Area di Housekeeping Department. Penelitian ini mengunakan metode deskriptif dengan pendekatan Research and Development. Studi pengembangan ini dilakukan dalam tiga tahap, meliputi: Tahap pertama merupakan tahap studi pendahuluan, Tahap kedua merupakan tahap pengembangan model dan Tahap ketiga merupakan tahap uji validasi model. Subjek penelitian terdiri dari guru pengampu mata pelajaran Public Area dan praktisi dari housekeeping depatment. Teknik pengumpulan data dilakukan melalui wawancara, observasi, dan expert judgement. Analisis data penelitian dilakukan sesuai dengan prosedur dan karakteristik dari temuan data penelitian; untuk data kuantitatif dianalisis secara kuantitatif dan untuk data kualitatif dianalisis secara kualitatif. Temuan penelitian berkaitan dengan Model Competency Based Assessment pada pengembangan Job Performance Public Area di Housekeeping Department meliputi tahap perencanaan penilaian, instrumen penilaian, dan pelaksanaan penilaian. Instrumen penilaian terdiri dari tahap persiapan praktik, proses praktik, dan hasil praktik. Dari temuan penelitian dan hasil validasi dapat disimpulkan bahwa Alat Penilaian praktik Public Area dengan menerapkan model Competency Based Assessment "sangat layak" untuk diimplementasikan di SMK Akomodasi Perhotelan dan di Housekeeping Department pada saat melakukan penilaian terhadap Job Performance Public area.
\end{abstract}

Kata Kunci : Model, Competency Based Assessment, Job Performance, Public Area, Housekeeping Department. 


\section{COMPETENCY BASED ASSESSMENT MODEL ON JOB PERFORMANCE PUBLIC AREA DEVELOPMENT IN HOUSEKEEPING DEPARTMENT}

The purpose of this research is to apply a competency-based assessment model on the job performance of Public Area at Housekeeping Department. The scope of the study produced 2 targets in housekeeping department: 1) competency based assessmen model on the job performance of public area; 2) assessment tool on job performance of public area. This study was used a descriptive method with three stages of development study. First is a preliminary study, second stage is development model, and finally is validation test of the model. The research subject was teacher of public area subject matter, and employees of housekeeping department. Data was collected through interviews, observations, and expert judgment. Data was analyzed in accordance with the procedures and characteristic of the findings. It was used both the qualitative and quantitative data. The finding showed that competency-based assessment model on the job performance of public area in housekeeping department included the planning, the instrument and the process of assessment stages. The instrument consisted of the preparation, practices, and outcome of assessment stages. The conclusion is assessment tools on the public area practices using competency-based assessment is very appropriate to apply this competency-based assessment at senior vocational high school, especially for job performance on housekeeping department expertise.

Keywords: Model, Competency Based Assessment, Job Performance, Public Area, Housekeeping Department

\section{PENDAHULUAN}

Pendidikan Kesejahteraan Keluarga sebagai pendidikan kejuruan, berupaya untuk menghasilkan lulusan yang berkuaitas, yaitu sarjana pendidikan yang secara akademis dan profesional berkontribusi bagi peningkatan mutu sumber daya manusia. Oleh karena itu, kompetensi lulusan Program Studi Pendidikan Kesejahteraan Keluarga diantaranya harus menunjukkan kemampuan sebagai Pendidik pada jalur pendidikan formal yaitu sebagai Guru SMK Bidang Keahlian Akomodasi Perhotelan. Profil lulusan tersebut dapat terwujud apabila didukung oleh layanan akademik yang mampu memberikan pengalaman belajar dalam bentuk perkuliahan dan penilaian sesuai dengan Kerangka Kualifikasi Nasional Indonesia (KKNI) yang dapat menunjukkan kemampuan kerja, sehingga lulusan memperoleh pengakuan dunia kerja (stakeholders). Kemampuan kerja ini diasumsikan dapat membekali mahasiswa calon guru dalam melaksanakan tugas mengajar dan profesional dengan segala perubahan dan tuntutannya. Dalam kaitannya dengan penilaian, sebagai calon guru SMK Akomodasi Perhotelan perlu adanya pengalaman di dalam mengembangkan alat penilaian sesuai Job Performance di Housekeeping Department.

Penilaian yang dapat diterapkan untuk mengukur kompetensi peserta didik di SMK Akomodasi Perhotelan adalah Performance Assessment melalui penerapan model Competency Based Assessment. Penilaian berbasis kom Cpetensi (Competency Based Assessment) yang diterapkan pada pendidikan kejuruan diarahkan untuk mengukur dan menilai performansi peserta didik dalam kemampuan kognitif, psikomotor dan afektif; baik secara langsung pada saat melakukan aktivitas belajar maupun secara tidak langsung, yaitu melalui bukti hasil belajar (evidence of learning) sesuai dengan kriteria kinerja (performance criteria). Kriteria kinerja tersebut harus sesuai dengan tuntutan dunia kerja, karena pada akhirnya kompetensi yang telah dikuasai oleh peserta didik atau lulusan harus mendapat pengakuan dari pihak pemakai tenaga kerja. Keberhasilan pendidikan kejuruan dapat dianalisis berdasarkan ukuran ganda, yaitu kualitas menurut ukuran standar sekolah atau lembaga pendidikan dan ukuran masyarakat atau pengguna Iulusan (Finch dan Crunkilton, 1984). Kriteria pertama meliputi aspek keberhasilan peserta didik dalam 
memenuhi tuntutan kurikulum yang telah diorientasikan pada tuntutan dunia kerja, sedangkan kriteria kedua meliputi keberhasilan peserta didik yang tertampilkan pada job performance yang sesuai dengan Standar Operasiona Prosedur (SOP) industri sebagai pengguna lulusan. Temuan dari hasil penelitian Suryandari (2013), bahwa Performance Assessment dalam evaluasi pembelajaran pada peserta didik di SMK dapat memberikan pengaruh yang bagus terhadap sikap peserta didik (efektivitas kinerja, keberhasilan, kerapihan dan menarik kesimpulan dalam melaksanakan proses pembelajaran praktik).

Competency Based Assessment diterapkan pada saat mengembangkan Job Performance kompetensi keahlian atau unjuk kerja peserta didik sesuai tuntutan SOP, diantaranya adalah Job Performance Pubic area di Housekeeping Department. Alat penilaian praktik public area di SMK merupakan komponen penting bagi guru untuk melaksanakan proses penilaian terhadap peserta didik pada saat melaksanakan praktik yang sesuai dengan SOP Hotel, agar peserta didik terbiasa apabila terjun ke dunia kerja di bidang housekeeping. Di samping itu, alat penilaian yang sesuai dengan SOP Hotel dapat memberikan kemudahan bagi guru dalam menilai peserta didik saat melaksanakan praktik di sekolah. Sesuai dengan perkembangan dunia pendidikan pada era globalisasi ini menuntut adanya penyesuaian sistem pendidikan yang selaras dengan tuntutan perkembangan teknologi dan dunia kerja, karena muara dari suatu proses pendidikan khususnya pada penyelenggaraan pendidikan kejuruan adalah dunia kerja. Sistem pendidikan yang dilaksanakan pada pendidikan kejuruan seyogianya mampu memberikan kesempatan kepada mahasiswa untuk membelajarkan diri dalam mengaktualisasikan semua potensi yang dimilikinya menjadi kemampuan profesional yang dapat dimanfaatkan dalam dunia kerja. (Finch dan Crunkilton, 1984).

Upaya dalam mengantisipasi tuntutan kompetensi di dunia kerja, maka program studi Pendidikan Kesejahteraan Keluarga memuat komponen mata kuliah teori dan mata kuliah praktik. Mata kuliah teori ialah yang memberikan pemahaman tentang konsep dasar dan wawasan keilmuan yang dilaksanakan dalam bentuk perkuliahan dan responsi di kelas. Mata kuliah praktik terdiri dari: (1) Praktik peningkatan keterampilan dan wawasan industri dilaksanakan di indstri-industri yang sesuai dengan bidang keahlian melalui Praktek Industri; (2) Praktik peningkatan wawasan dan keahlian profesi guru dilaksanakan di Sekolah Menengah Kejuruan melalui Program Pengalaman Lapangan.

\section{METODE PENELITIAN}

\section{Pendekatan Penelitian}

Pendekatan penelitian yang digunakan untuk menjawab masalah penelitian yang telah dirumuskan dalam penelitian ini adalah Research and Development (R\&D). Langkah penelitian Research and Development dalam penelitian ini meliputi tiga tahap, yaitu : (1) Studi Pendahuluan, (2) Pengembangan Model dan (3) Uji Model (Validasi Model). (Disarikan dari Sukmadinata: 2005).

\section{Lokasi dan Subjek Penelitian}

Penelitian dilakukan pada lembaga institusi pasangan tempat pelaksanaan praktek industri bidang keilmuan dan keahlian Tata Graha, yaitu Hotel di Kota dan Kabupaten Bandung dan SMK Akomodasi Perhotelan sebagai sekolah mitra. Subjek penelitian terdiri dari guru pengampu mata pelajaran public area dan praktisi dari housekeeping department.

\section{Teknik Pengumpulan dan Analisis Data}

Pengumpulan data penelitian dikelompokkan dalam tiga bagian, yaitu:

a. Studi Pendahuluan

Pada studi pendahuluan dipilih teknik wawancara, observasi, dan studi dokumentasi yang ditunjang dengan kajian literatur, untuk menghasilkan model Competency Based Assessment pada Job Performance Publik area di Housekeeping Departement.

b. Pengembangan Model 
Pada tahap pengembangan model, dilakukan perancangan alat penilaian public area dengan menerapkan Competency Based Assessment sesui SOP Hotel dan menganalisis alat penilaian secara teoritik dan empirik.

c. Uji Model (Validasi Model)

Pada tahap validasi dilakukan untuk menguji keunggulan dari model yang dikembangkan melalui expert judgement.

Teknik analisis data yang dilakukan mencakup analisis data pada tahap studi pendahuluan, pengembangan model dan validasi model dianalisis menggunakan pendekatan kualitatif.

\section{HASIL DAN PEMBAHASAN}

\section{Perancangan Alat Penilaian Praktik Public Area}

Perancangan pada alat penilaian praktik tahap persiapan meliputi tiga aspek yaitu penampilan diri, persiapan peralatan pembersih lobby area, dan persiapan bahan pembersih. Tahap persiapan perlu dilakukan oleh peserta didik agar memberikan kemudahan dalam melaksanakan pekerjaan dengan menyesuaikan indikator-indikator yang ada pada SOP Hotel.

Tabel 1. Penilaian Persiapan Praktik Public Area

\begin{tabular}{|c|c|c|c|c|}
\hline \multirow{2}{*}{ No } & Indikator Penilaian Sebelum Revisi & Indikator Penilaian Sesudah Revisi & \multirow{3}{*}{ Ya } & \multirow[b]{2}{*}{ Tidak } \\
\hline & $\begin{array}{c}\text { Tahap persiapan Praktik Public } \\
\text { Area }\end{array}$ & Tahap persiapan Praktik Public Area & & \\
\hline & 1. Penampilan Diri & 1. Penampilan Diri & & \\
\hline & $\begin{array}{l}\text { a. Mengenakan seragam yang telah } \\
\text { disediakan }\end{array}$ & $\begin{array}{l}\text { a. Mengenakan seragam yang telah } \\
\text { disediakan }\end{array}$ & & \\
\hline & $\begin{array}{l}\text { b. Berpenampilan rapih dan bersih } \\
\text { serta sopan }\end{array}$ & $\begin{array}{l}\text { b. Berpenampilan rapih dan bersih serta } \\
\text { sopan }\end{array}$ & & \\
\hline & $\begin{array}{l}\text { c. Bagi laki-laki rambut pendek } \\
\text { diatas kerah }\end{array}$ & $\begin{array}{l}\text { c. Bagi laki-laki rambut pendek diatas } \\
\text { kerah }\end{array}$ & & \\
\hline & $\begin{array}{l}\text { d. Bagi wanita bila rambut panjang } \\
\text { harus diikat/digelung }\end{array}$ & $\begin{array}{l}\text { d. Bagi wanita bila rambut panjang harus } \\
\text { diikat/digelung }\end{array}$ & & \\
\hline & $\begin{array}{l}\text { e. Tidak menggunakan accessories } \\
\text { yang berlebihan }\end{array}$ & $\begin{array}{l}\text { e. Tidak menggunakan accessories yang } \\
\text { berlebihan }\end{array}$ & & \\
\hline & $\begin{array}{l}\text { f. Bagi wanita tidak menggunakan } \\
\text { make-up berlebihan }\end{array}$ & $\begin{array}{l}\text { f. Bagi wanita tidak menggunakan make- } \\
\text { up berlebihan }\end{array}$ & & \\
\hline & $\begin{array}{l}\text { g. Tidak berkumis dan berjenggot } \\
\text { bagi laki-laki, kebersihan tangan, } \\
\text { kaki, badan }\end{array}$ & $\begin{array}{l}\text { g. Tidak berkumis dan berjenggot bagi } \\
\text { laki-laki, kebersihan tangan, kaki, } \\
\text { badan }\end{array}$ & & \\
\hline & h. Kebersihan gigi & h. Kebersihan gigi & & \\
\hline & $\begin{array}{l}\text { 2. Persiapan Peralatan Pembersih } \\
\text { Lobby Area }\end{array}$ & $\begin{array}{l}\text { 2. Persiapan Peralatan Pembersih } \\
\text { Lobby Area }\end{array}$ & & \\
\hline & a. Public Area Trolley & a. Public Area Trolley & & \\
\hline & b. Wet Mop & b. Wet Mop & & \\
\hline & c. Lobby Duster & c. Lobby Duster & & \\
\hline & d. Dusthing Cloth & d. Dusthing Cloth & & \\
\hline & e. Window Squeeze & e. Window Squeeze & & \\
\hline & f. $\quad$ Ceiling Broom & f. Ceiling Broom & & \\
\hline & g. Double Caster Brucket & g. Double Caster Brucket & & \\
\hline
\end{tabular}




\begin{tabular}{clll}
\hline No & Indikator Penilaian Sebelum Revisi & \multicolumn{1}{c}{ Indikator Penilaian Sesudah Revisi } \\
\hline A & \multicolumn{1}{c}{$\begin{array}{c}\text { Tahap persiapan Praktik Public } \\
\text { Area }\end{array}$} & \multicolumn{1}{c}{ Tahap persiapan Praktik Public Area } & Ya Tidak \\
\hline & \multicolumn{1}{c}{-} & & \\
\hline 3. Persiapan Bahan Pembersih & 3. Floor Polisher \\
\hline a. Glass Cleaner & a. Glass Cleaner \\
\hline b. Marble Powder & b. Marble Powder \\
\hline c. Ameral & c. Ameral \\
\hline d. Wood Polish & d. Wood Polish \\
\hline
\end{tabular}

Tahap proses praktik meliputi prosedur pembersihan di hotel sesuai dengan SOP yang ada. Prosedur pembersihan terdapat sebelas indikator yang harus dilakukan sesuai dengan SOP Hotel.

Tabel 2. Penilaian Proses Praktik Public Area

\begin{tabular}{|c|c|c|c|}
\hline $\begin{array}{ll}\text { No } \\
B\end{array}$ & Indikator Penilaian & Ya & Tidak \\
\hline & Tahap Proses Praktik Public Area & & \\
\hline & Prosedur pembersihan lobby area meliputi: & & \\
\hline & a. Siapkan peralatan dan chemical untuk menunjang kebersihan & & \\
\hline & b. Ganti dan bersihkan ashtray yang kotor & & \\
\hline & $\begin{array}{l}\text { c. Ambil sampah yang berceceran. Laporkan bila ada barang tamu yang } \\
\text { tertinggal ke suvervisor }\end{array}$ & & \\
\hline & d. Kosongkan tong sampah dan bersihkan & & \\
\hline & e. Bersihkan semua kaca dan jendela & & \\
\hline & f. Dust furniture, hiasan dan lobby telephones & & \\
\hline & $\begin{array}{l}\text { g. Angkat noda di dinding dan picture, dust atas dan samping setiap picture } \\
\text { frames }\end{array}$ & & \\
\hline & h. Bersihkan keramik lantai (mopping) & & \\
\hline & i. $\quad$ Vacuum karpet area & & \\
\hline & j. Rapihkan furniture, sofa, dan vacuum kursi bila perlu & & \\
\hline & k. Apabila ada semut, kecoa dalam area lobby segera hubungi pest control & & \\
\hline
\end{tabular}

Perancangan pada alat penilaian praktik tahap hasil meliputi dua aspek, yaitu permukaan lantai dan kesesuaian prosedur pembersihan. Tahap hasil ini merupakan tahap akhir dari proses praktik public area.

Tabel 3. Penilaian Hasil Praktik Public Area

\begin{tabular}{|c|c|c|c|c|}
\hline No & Indikator Penilaian Sebelum Revisi & Indikator Penilaian Sesudah Revisi & Ya & Tidak \\
\hline \multirow[t]{6}{*}{ C } & Tahap Hasil Praktik Public Area & Tahap Hasil Praktik Public Area & & \\
\hline & 1. Permukaan lantai terlihat: & 1. Permukaan lantai terlihat: & & \\
\hline & a. Bersih & a. Bersih & & \\
\hline & b. Mengkilap & b. Mengkilap & & \\
\hline & c. Wangi & c. Wangi & & \\
\hline & $\begin{array}{l}\text { 2. Kesesuaian waktu prosedur } \\
\text { pembersihan }\end{array}$ & $\begin{array}{l}\text { 2. Kesesuaian waktu prosedur } \\
\text { pembersihan }\end{array}$ & & \\
\hline
\end{tabular}




\section{Dapat membersihkan lobby area Waktu dalam proses pembersihan dapat \\ dalam waktu 10 menit disesuaikan dengan lokasi dan ruangan \\ lobby area}

\section{Hasil Analisis Perancangan Alat Penilaian Praktik Public Area}

\section{a. Tahap Persiapan}

Indikator pada tahap persiapan diri berdasarkan hasil validasi dari ahli praktisi yaitu ahli housekeeping hotel dan guru mata pelajaran public area menyatakan bahwa alat penilaian tersebut sangat layak digunakan untuk melaksanakan persiapan sebelum melakukan praktik. Persiapan penampilan diri ini wajib dilakukan oleh peserta didik sebelum melakukan praktik public area. Penampilan diri adalah penampilan yang dari segi fisik maupun mental dapat dipertanggungjawabkan perwujudannya, baik kepada tamu, atasan, maupun sesama karyawan dan sikap yang sopan, selalu siap melaksanakan tugas dengan penuh keramahan dan rasa tanggungjawab (Suwithi, 2008).

Persiapan penampilan diri yaitu sudah memuat indikator yang sesuai dengan SOP hotel. Tahap persiapan penampilan diri yang sudah sesuai dan dapat diterapkan pada peserta didik berdasarkan pendapat Suwithi (2008) meliputi menggunakan seragam yang telah disediakan, berpenampilan rapih dan bersih serta sopan, menjaga kebersihan tangan, kaki, badan, dan kebersihan gigi bagi pria rambut pendek di atas kerah, tidak berkumis dan berjenggot, bagi wanita bila rambut panjang harus diikat atau digelung, tidak mengenakan assessories yang berlebihan, tidak menggunakan make-up berlebihan,

Indikator pada peralatan pembersih lobby area berdasarkan hasil validasi dari ahli praktisi yaitu ahli housekeeping hotel dan guru mata pelajaran public area menyatakan bahwa alat penilaian sudah sesuai dengan SOP hotel dan sangat layak untuk digunakan peserta didik dalam proses pembersihan, namun terdapat revisi sesuai saran dari ahli penilaian untuk ditambahkan peralatan floor polisher sebagai alat yang biasa digunakan untuk mengkilapkan lantai.

Komponen penilaian peralatan pembersih lobby area sudah sesuai dengan SOP yang ada di hotel. Terdapat beberapa jenis peralatan pembersih yang dipergunakan sebagai pendukung utama pada housekeeping department pada saat melakukan perawatan dan pembersihan area hotel yang menjadi tanggungjawabnya (Suwithi, 2008, hlm. 197). Tahap persiapan peralatan pembersih lobby area berdasarkan pendapat Rumekso (2008, hlm. 148-152) harus dipersiapkan sebelum melaksanakan praktik dapat meliputi public area trolley, mop, lobby duster, dusthing cloth, window squeegee, ceiling broom, double caster brucket, vacuuming.

Persiapan peralatan pembersih lobby area perlu dilakukan oleh peserta didik, agar dapat memperlancar proses kerja yang dilakukan. Sebelum melaksanakan kegiatan pembersihan harus mempersiapkan semua perlengkapan pembersihan (Bagyono, 2009). Apabila persiapan tidak dilakukan peserta didik pada saat melaksanakan praktik dapat memakan waktu yang cukup lama, maka dari itu perlu adanya persiapan peralatan pembersih lobby area.

Indikator pada tahap persiapan berdasarkan hasil validasi dari ahli praktisi yaitu ahli housekeeping hotel menyatakan alat penilaian tersebut layak, dan dari guru mata pelajaran public area menyatakan sangat layak. Kriteria layak dari praktisi hotel ini disebabkan kurang sesuainya prosedur waktu pembersihan karena pada indikator ketepatan waktu dalam penggunaan alat pada saat praktik dapat disesuaikan dengan lokasi dan ruangan lobby area, sebab tidak semua hotel memiliki lokasi dan ruangan dengan luas yang sama..

Penilaian bahan pembersih pada tahap persiapan sudah memuat indikator-indikator yang sesuai dengan SOP hotel. Tahap persiapan bahan pembersih berdasarkan pendapat Rumekso (2008, hlm.162170) dapat meliputi glass cleaner, marble powder, ameral, dan wood polish.

\section{b. Tahap Proses}


Alat penilaian tahap proses praktik public area memuat prosedur pembersihan yang akan dilakukan. Tahap proses ini terdapat sebelas indikator yang dapat dilakukan oleh peserta didik. Indikator-indikator tersebut sudah sesuai dengan SOP di hotel dengan meliputi menyiapkan peralatan dan bahan pembersih untuk menunjang kebersihan, mengganti dan membersihkan ashtray yang kotor, mengambil sampah yang berceceran serta melaporkan bila ada barang tamu yang tertinggal ke suvervisor, membersihkan tempat sampah, membersihkan semua kaca dan jendela, dust furniture, hiasan dan lobby telephones, angkat noda di dinding dan picture, dust atas dan samping setiap picture frames, membersihkan keramik lantai (mopping), membersihkan karpet area menggunakan vacuum, merapihkan furniture, sofa dan vacuum kursi bila perlu, apabila ada semut, kecoa dalam area lobby segera hubungi pest control.

Data hasil validasi dari ahli praktisi yaitu ahli housekeeping hotel dan guru mata pelajaran public area menyatakan tahap proses prosedur pembersihan pada alat penilaian sangat layak untuk digunakan oleh guru sebagai prosedur pembersihan yang akan dilakukan peserta didik dalam praktik public area.

Semua indikator harus dilakukan sesuai dengan tahapan praktik. Praktik public area harus dikerjakan secara sungguh-sungguh karena public area merupakan area umum yang sering dikunjungi oleh tamu, sehingga harus tetap terjaga kebersihan, kerapihan, keindahan dan kenyamanannya (Rumekso, 2008).

\section{c. Analisis dan Perancangan Alat Penilaian Tahap Hasil}

Indikator-indikator tahap hasil berdasarkan hasil validasi dari ahli praktisi yaitu ahli housekeeping hotel dan guru mata pelajaran public area menyatakan layak dan sangat layak. Kriteria layak menunjukkan sudah bagus, namun terdapat revisi sesuai saran dari ahli praktisi hotel dimana perlu adanya perbaikan dan penambahan pada waktu praktik dalam pembersihan yang akan dilaksanakan oleh peserta didik dapat disesuaikan dengan ruangan atau lokasi yang akan dibersihkan. Hal ini karena setiap hotel tidak memiliki lokasi dan luas ruangan lobby area yang sama.

Tahap hasil praktik public area yang dirancang memiliki dua aspek yaitu permukaan lantai dan kesesuaian prosedur pembersihan yang didalamnya terdapat empat indikator yaitu lantai bersih, mengkilap, wangi dan waktu yang dipergunakan praktik peserta didik 10 menit. Sejalan dengan pendapat Bagyono (2009) menyatakan bahwa area umum yang bersih dan mengkilap akan memberikan sugesti kepada tamu bahwa mereka juga akan mendapatkan perhatian dan perawatan yang sama baiknya seperti perlakuan terhadap kamar tamu.

\section{d. Analisis Hasil Verifikasi dan Validasi Alat Penilaian Praktik Public Area}

Hasil validasi yang telah dilakukan kepada tiga validator menghasilkan spesifikasi alat penilaian praktik public area"sangat layak" dilihat dari penilaian berdasarkan 1) isi indikator pada alat penilaian sudah sesuai dengan SOP hotel, 2) kebahasaan menggunakan bahasa sesuai dengan kaidah bahasa Indonesia dengan menggunakan bahasa yang sederhana serta mudah dimengerti dan menggunakan istilah-istilah yang mudah dipahami oleh peserta didik, 3) penyajian ditulis dengan singkat, jelas dan terperinci, 4) efek media terhadap strategi pembelajaran dapat mempermudah guru dalam menilai peserta didik ketika melaksanakan praktik public area, 5) tampilan menyeluruh sudah sesuai. Sejalan dengan pendapat Suharsimi, Arikunto (2010, hlm. 44) bahwa kriteria sangat layak dapat dilihat berdasarkan isi, kebahasaan, penyajian, efek media terhadap strategi pembelajaran dan tampilan menyeluruh. Berdasarkan persentase hasil validasi alat penilaian praktik public area menghasilkan kategori "sangat layak", hal tersebut dikarenakan mengacu pada skala persentase menurut Sudjana (2005, hlm.91) bahwa persentase pencapaian termasuk kedalam katergori "sangat layak".

\section{SIMPULAN}

Model Competency Based Assessment pada pengembangan Job Performance Public Area di Housekeeping Department yang dihasilkan memiliki keunggulan karena dilakukan melalui tahapan 
identifikasi kebutuhan, analisis teoritis dan empirik, uji validasi melalui expert judgement ahli dan praktisi di bidang housekeeping.

Hasil validasi alat penilaian praktik public area yang telah dirancang dikategorikan "Sangat layak", artinya alat penilaian dapat diimplementasikan di SMK Akomodasi Perhotelan dan di Housekeeping Department pada saat melakukan penilaian terhadap Job Performance Public area.

\section{DAFTAR PUSTAKA}

Bagyono. 2009. Manajemen Housekeeping Hotel. Bandung: alfabeta.

Finch, C. dan Crunkilton, J.R. 1984. Curriculum Development in Vocational and Technical Education:

Planning, Content and Implementation. Boston: Allyn and Bacon, Inc.

Rumekso. 2008. Housekeeping Hotel Public Area/Houseman Section. Yogyakarta: Andi.

Sudjana. 2005. Metode Statistika. Bandung: Tarsito.

Sukmadinata, N.S. 2005. Metode Penelitian Pendidikan. Bandung : PT Remaja Rosdakarya.

Suryandari, T. 2013. Performance Assessment Sebagai Instrumen Penilaian Untuk Meningkatkan Keterampilan Proses Pada Praktikum Kimia Dasar Di Tadris Kimia. Jurnal Phenomenon, Volume 3 Nomor 2.

Suwithi, N. 2008. Akomodasi Perhotelan. Jilid 2. Jakarta: Direktorat Pembinaan Sekolah Menengah Kejuruan 